\title{
Kinetics of TNT Degradation in The Presence of Zero Valent Iron Nanocatalyst
}

\author{
A.M. Badawi ${ }^{1}$, Seham A. Shaban ${ }^{1}$, Sahar M. Ahmed ${ }^{1}$, Salwa \\ M.I. Morsy ${ }^{1,2}$ and A.Y. El-Naggar ${ }^{1,2}$ \\ ${ }^{I}$ Egyptian Petroleum Research Institute, Nasr City ,Cairo, \\ Egypt and ${ }^{2}$ Chemistry Department, Faculty of Science, Taif \\ University, Saudi Arabia.
} HE REDUCTION of 2,4,6-trinitrotoluene (TNT) in aqueous
solution using nanoscale zero-valent iron was investigated. The
results showed that the first order reaction law fits the reduction of
TNT. The measured apparent rate constant (Kobs) of TNT on
nanoscale zero-valent iron $\left(0.0374 \mathrm{~h}^{-1}\right)$ was 4-fold than on
conventional iron powders $\left(0.0091 \mathrm{~h}^{-1}\right)$ at $303 \mathrm{~K}$. The apparent rate
constant of TNT reduction on nanoscale zero-valent iron also can be
improved by an increase in concentration of nanoscale zero-valent iron
and a decrease of pH.

Keywords : Environmentally, Nanotechnologies, Pollution, Nanoiron, Wastewater and Explosive.

2,4,6-Trinitrotoluene (TNT) is known as one of the high explosive compounds, this nitro aromatic compound has been widely used in military and civilian blasting. As TNT is insoluble in water and toxic, carcinogenic, and mutagenic ${ }^{(1)}$, the extensive use of TNT poses environmental risk $^{(2)}$. Hence, removal of TNT from soil, surface water and ground water has attracted a lot of attention. Cleanup of TNT contaminated sites is required since TNT poses significant risks to human health and can be pernicious to aquatic and terrestrial organisms ${ }^{(2)}$. There are many methods used for the removal of TNT from aqueous solution ${ }^{(3-7)}$, including adsorption, evaporation, membrane extraction and flotation. However, these physical methods only transfer TNT from one phase to another. In addition, chemical methods such as incineration, advanced oxidation, Fenton oxidation, chemical precipitation and chemical reduction need high operation costs or may produce intermediate products, which are also toxic to the environment ${ }^{(4-7)}$. In the recent years, zero-valent iron has been used extensively to reduce organic pollutants ${ }^{(8,9)}$. The use of zero valent iron as a permeable reactive barrier (PRBs) systems in groundwater treatment started in early $1990 \mathrm{~s}^{(10,11)}$. In a PRB structure, groundwater flows passively through a PRBs while contaminants are precipitated, adsorbed, or transformed in contact with the zero-valent iron surface. Although PRBs containing zero valent iron powders are useful in situ remedies for some sites, costs associated with the PRB construction and the relative lack of flexibility for installing the PRB still exist for this technology, which may limit its practical application ${ }^{(12)}$. 
The nanoscale zero-valent iron technology can be regarded as an extension of the zero-valent iron technology. In some cases, it may serve as an alternative to the conventional zero-valent iron PRBs ${ }^{(12-14)}$. Because of their small particle size, nanoscale zero-valent iron is a promising environmental-friendly material used in removing contaminations from wastewater, which has been receiving considerable attentions for its potential applications in groundwater treatment and site remediation $^{(15,16)}$. The nanoscale zero-valent iron has been successfully used for in situ dechlorination reduction of several chlorinated aliphatic compounds ${ }^{(17,18)}$, polychlorinated biphenyls, and a mixture of $\mathrm{PCBs}^{(19,20)}$. Aromatic nitro compounds reduction by iron metal have been reported ${ }^{(21)}$, in which nitro groups transformed to amines groups and these products are prone to be biodegraded ${ }^{(22,23)}$, however there is little study on the kinetics of TNT reduction by nanoscale zero-valent iron. The aim of this study is to investigate the kinetics of TNT reduction in aqueous solution using nanoscale zero-valent iron. The effects of concentration of nanoscale zero-valent iron, $\mathrm{pH}$ and time on the reduction reaction kinetics of TNT were investigated. In addition, the comparisons of reaction rate constant and half-life of TNT reduction were done between the conventional iron powders and nanoscale zero-valent iron. The nanoscale zero-valent iron used to break down TNT from wastewater was explored, which may overcome the inherent limitations of conventional zero-valent iron, for example, nanoscale zero-valent iron has been proved to have improved efficiency for treating wastewater containing TNT and abilities to remove other aromatic compounds from wastewater.

\section{Experimental}

\section{Instruments}

1) X-ray diffraction was carried out for the catalyst samples, with a Phlips diffractometer (type pw1050) at $\lambda=1.54 \AA$. A Cu K $\alpha$ target with a nickel filter.

2) Surface area and pore volume of catalyst samples were analyzed by means of nitrogen adsorption using Nova 2000, Quanta Chrome (commercial BET unit).

3) TEM image and selected-area electron diffraction (SAED) was taken with a JEOL JEM-2000 EX model transmission electron microscope, using an accelerating voltage of $100 \mathrm{kv}$. The sample of TEM was prepared by two hours ultrasonic dispersion of $0.2 \mathrm{~g}$ of product in $50 \mathrm{ml}$ ethanol. Then, a drop of the solution was placed on a copper micro grid, and dried in air before performance.

Synthesis of iron nanocatalysts zero valent by reduction with hydrazine hydrate

A clear iron solution in ethylene glycol was prepared by dissolving a certain amount of iron salt $\left(\mathrm{FeSO}_{4}\right)$ in $50 \mathrm{ml}$ of ethylene glycol. Heating at $90^{\circ} \mathrm{C}$ attained complete solubility of the salt. The iron metal was obtained from the prepared solutions by adding different amounts of hydrazine hydrate $\left(\mathrm{N}_{2} \mathrm{H}_{2} \cdot \mathrm{H}_{2} \mathrm{O}\right)$ solution $(80$ vol. \%) drop wisely to the previously prepared solution of iron salt in ethylene glycol under constant stirring (400-600 rpm). The addition of hydrazine resulted in changing the color of solution from blue to brown-reddish brown. After about $10 \mathrm{~min}$, sodium hydroxide solution was added till $\mathrm{pH}$ of the solution reached 11-12 after which a black solid precipitate of iron metals zero valent was

Egypt. J. Chem. 55, No. 4 (2012) 
precipitated. The obtained iron zero valent was collected after washing several times with organic solvent (acetone or alcohol). The sample was then dried at $80^{\circ} \mathrm{C}$.

\section{Chemicals and batch reactor}

Experiments were performed using (100 $\mathrm{ml} \mathrm{g} / \mathrm{l}) \mathrm{TNT}$ explosives dissolved in $3 \mathrm{mM} \mathrm{CaCl}_{2}$, which provided a background electrolyte concentration similar to groundwater. Solutions at three different $\mathrm{pH}$ levels $(4.7,7.4$, and 9.7) were placed in a flask containing accurately weighed amounts of the nanocatalyst samples. Constant $\mathrm{pH}$ levels were maintained during the batch experiments at room temperature using $\mathrm{pH}$ controller that dispensed $0.1 \mathrm{~N} \mathrm{HCl}$ and $0.1 \mathrm{~N} \mathrm{NaOH}$ solutions into the reactor. The nanocatalyst samples weight around $0.3 \mathrm{~g} / \mathrm{l}$ of solutions. The flasks were shaken at $200 \mathrm{rpm}$ using an electric shaker for a prescribed length of time to attain equilibrium. After filtration through the filter paper, TNT was analyzed using high performance liquid chromatography (HPLC) (Fuller et al., 2004).

The relevant physical and chemical properties of the nanocatalysts are presented in Table 1. Nanocatalysts with a wide range of particle sizes and specific surface areas were evaluated.

\section{Results and Discussion}

\section{Characterization of nanoscale zero-valent iron}

The products were firstly checked by XRD technique to learn their phase compositions. Figure 1 is the XRD pattern of nanoscale zero-valent iron, the reflection peaks at $2 \theta=19.3^{\circ}, 27.5^{\circ}$ and $33.8^{\circ}$ and $54.8^{\circ}$ correspond to the characteristic inter planar spacing between $\left(\begin{array}{lll}1 & 1 & 0\end{array}\right),\left(\begin{array}{lll}2 & 0 & 0\end{array}\right),\left(\begin{array}{lll}2 & 1 & 1\end{array}\right)$ and $\left(\begin{array}{lll}3 & 2 & 1\end{array}\right)$ planes of Fe-zero valent. Particle shape and size are important properties that may affect the properties of nanoparticles.

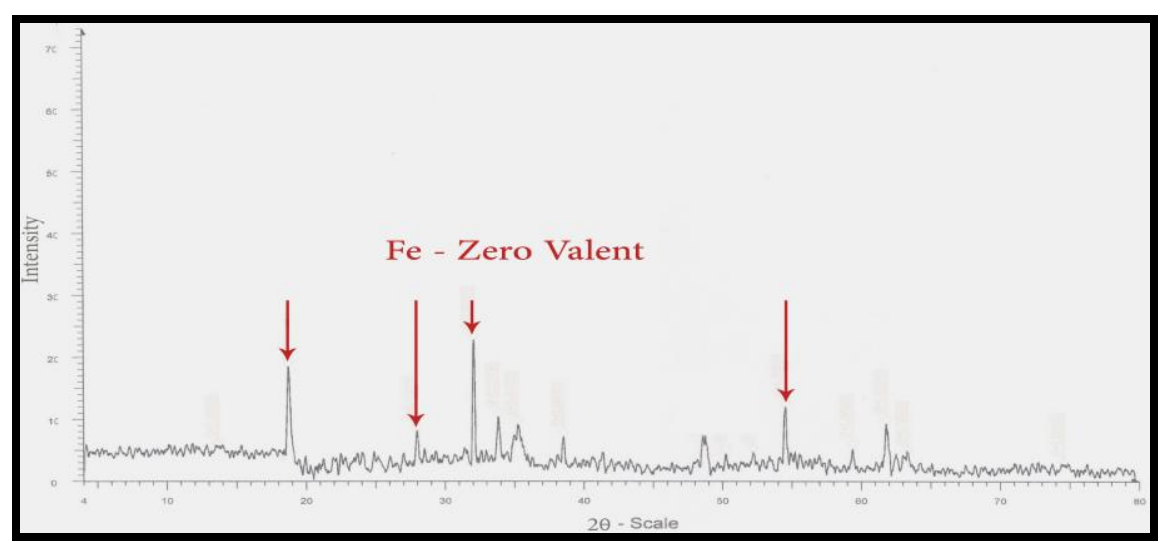

Fig. 1. XRD pattern of nanoscale zero-valent iron.

Egypt. J. Chem. 55, No. 4 (2012) 
Morphology of nanoscale zero-valent iron membranes for the purpose of clarifying the size of nanoiron, this nanoscale zero-valent iron was characterized by transmission electron microscope. Figure 2 shows the morphology and particle size of this nanoscale iron particles. Figure 2 shows the metal particles, which have a size generally less than $50 \mathrm{~nm}$. Similar results were also found in the recent years ${ }^{(24-26)}$.

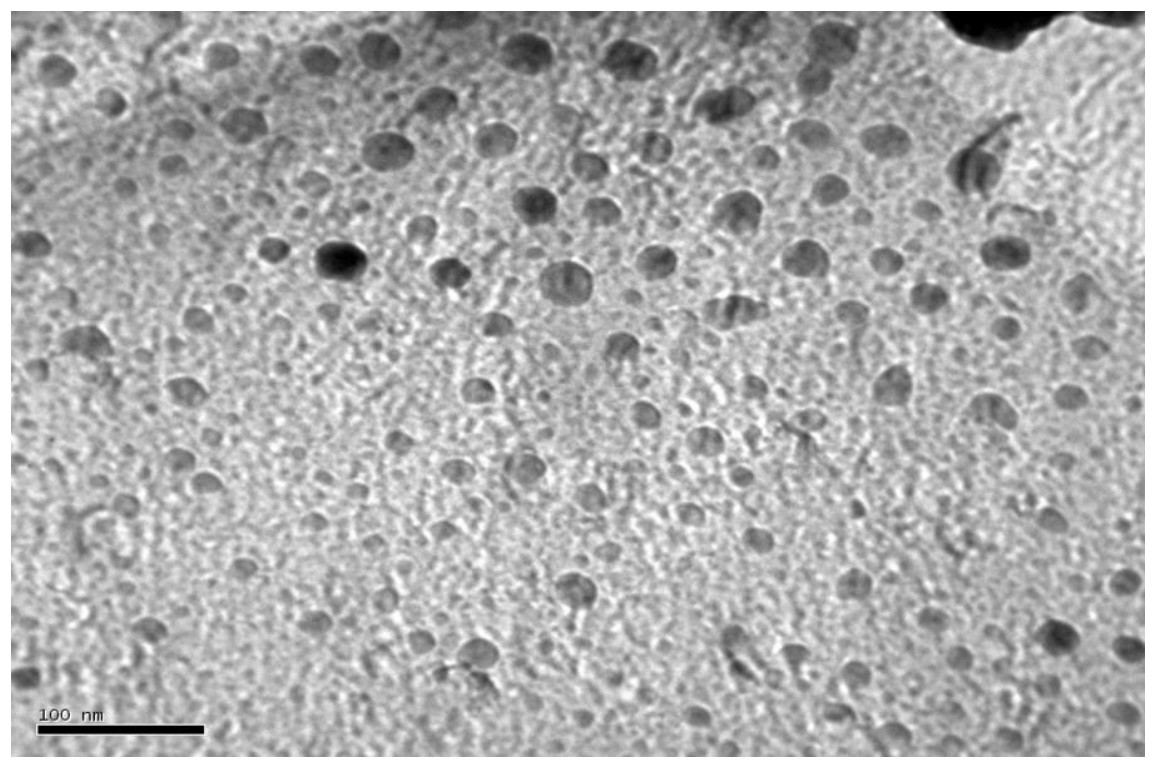

Fig. 2. TEM image of nanoscale zero-valent iron.

The surface texture properties of the samples have been assessed from nitrogen adsorption isotherms at $196^{\circ} \mathrm{C}$. The sample displayed type II (Fig. 3) in the IUPAC classification $^{(27)}$. The Fe-zero valent has a surface area of $214 \mathrm{~m} 2 \mathrm{~g}-1$ measured by Brunauer, Emmett and from Fig. (3), the investigated solid exhibited distribution in which Teller (BET) adsorption isotherms ${ }^{(28)}$. More detailed information on the pore size distribution is available from Fig. 3 constructed by plotting $d V p / d r$ against the pore radius ${ }^{(29)}$. It is seen that most of the pores were located in the micro-pore range. However, the maxima of the pore radius distribution curve are located at range of 18-50 $\AA$.

\begin{tabular}{|c|c|c|}
\hline Sample & Surface area, $\mathbf{~}^{\mathbf{2}} \mathbf{g}^{-\mathbf{1}}$ & Particle size, $\mathbf{n m}$ \\
\hline nanoscale zero-valent iron & 214 & 9.9 \\
\hline
\end{tabular}




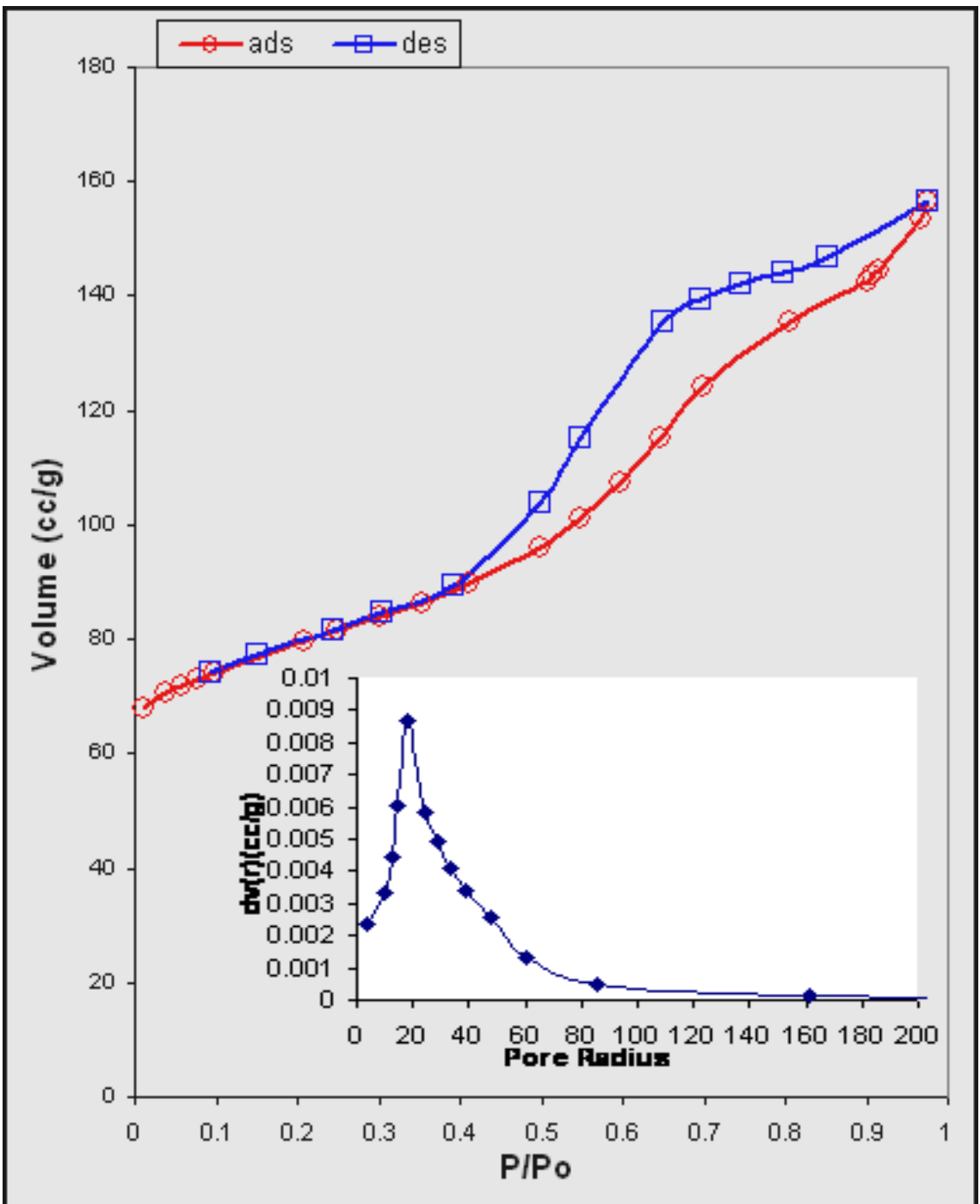

Fig. 3. Textural characteristics of nanoscale zero-valent iron.

Kinetics experiments of TNT reduction by nanoscale zero-valent iron

Typically, batch tests were undertaken by adding $0.3 \mathrm{~g}$ of nanoscale zerovalent iron into $100 \mathrm{ml}$ flasks in which bottle included $100 \mathrm{ml}$ of TNT stock solution (Stock solution of TNT was prepared by weighing out $100 \mathrm{mg}$ of TNT and transferring each to a $1000 \mathrm{ml}$ measuring flask), $\mathrm{pH}$ value at 4.7 . Then the 
flask was capped and processed on a rotary shaker $(150 \mathrm{rpm})$ at temperature $30^{\circ} \mathrm{C}$. At certain time intervals of this reaction, the sample was taken and separated from the solution by centrifugation at $3500 \mathrm{rpm}$ for $5 \mathrm{~min}$. As shown in Fig. 4, the rate of reduction of TNT on nanoscale zero-valent iron was very fast, and the residual concentration of TNT in solution decreased sharply in the first hour. As nanoscale zero-valent iron has relatively large surface area and strong adsorption capacity, TNT from aqueous solution was adsorbed mainly on the surface of nanoscale zero-valent iron and adsorption rate is faster than the reduction rate of TNT by nanoscale zero-valent iron at the beginning stage ${ }^{(30)}$, which means that the adsorption phenomenon of TNT is dominating at this stage ${ }^{(31)}$. Subsequently the reaction rate decreased, as can be concluded by the curve which declines slowly. It was observed that TNT residual concentration was less than $0.1 \mathrm{mg} / \mathrm{L}$ after $2 \mathrm{hr}$ of reaction and thereafter the residual concentration of TNT in solution was below the detection limit.

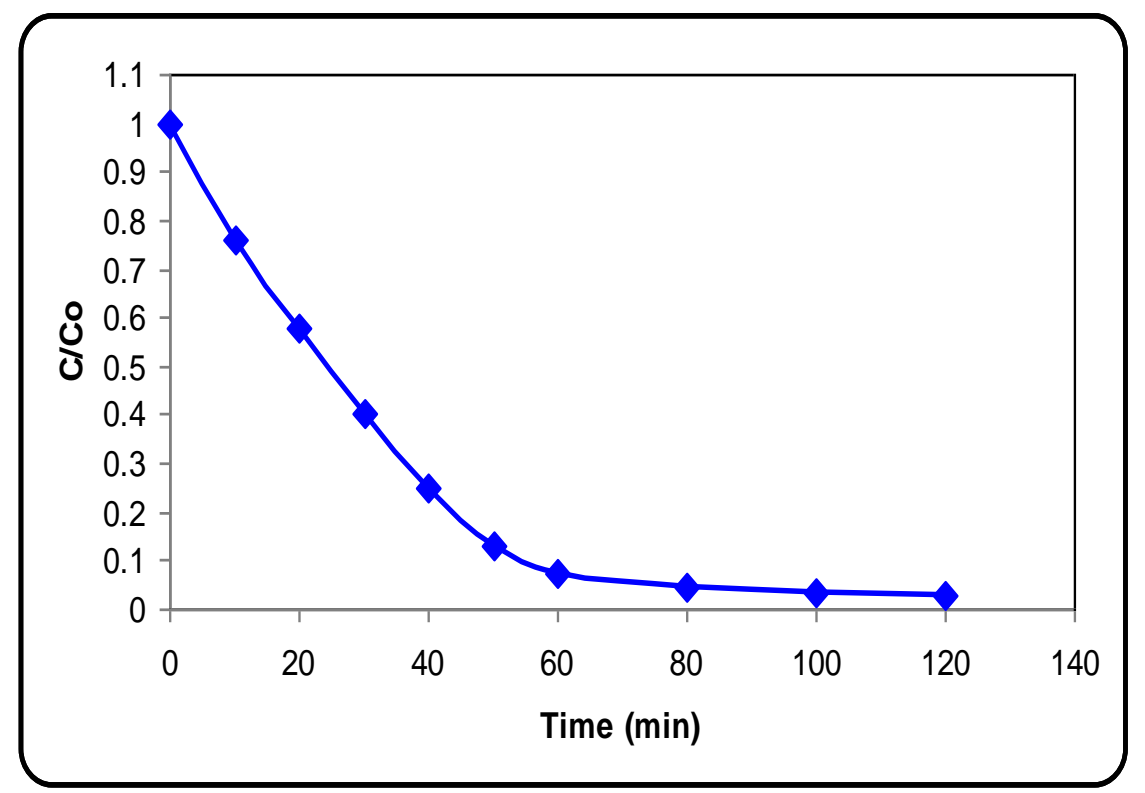

Fig. 4. Concentration variation of TNT with time on nanoscale zero-valent iron.

The logarithmic plots of residual concentration of TNT in solutions versus time are shown in Fig. 5 which indicates that $\ln \left(\mathrm{c} / \mathrm{c}_{\mathrm{o}}\right)$ and time have a good linear relationship and the correlation coefficient $\left(\mathrm{R}_{2}\right)$ is larger than 0.98. It was concluded that the rate of TNT reduction by nanoscale zero-valent iron can be described by the first-order reaction.

Egypt. J. Chem. 55, No. 4 (2012) 


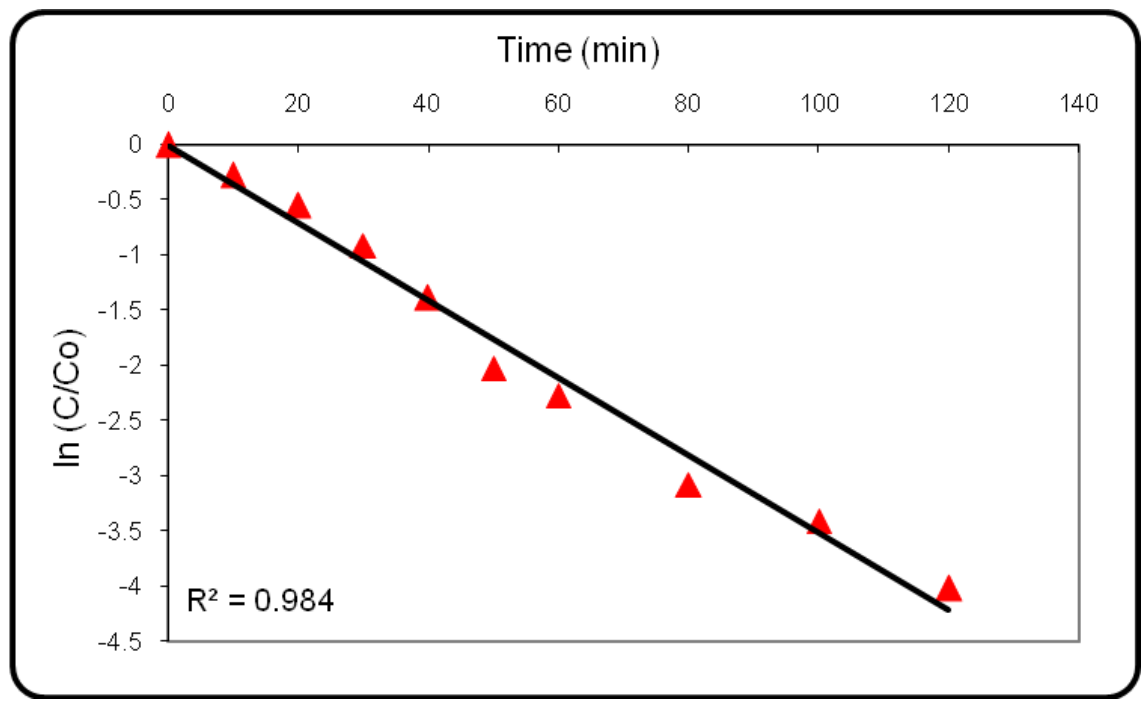

Fig. 5. Relationship between logarithmic plots of TNT concentration versus time on nanoscale zero-valent iron.

Effects of different initial nanoscale zero-valent iron concentration on the reduction rate of TNT

Batch tests were completed on a condition that different initial concentrations of nanoscale zero-valent iron were applied to reduce $100 \mathrm{mg} / \mathrm{l}$ of TNT stock solutions without adjusting $\mathrm{pH}$. Mixed solutions were processed on a rotary shaker $(150 \mathrm{rpm})$ at temperature $30{ }^{\circ} \mathrm{C}$. Figure 6 shows the TNT rate of reduction at different nanoscale zero-valent iron concentrations, which demonstrates that all followed the first-order kinetics model when the reductions of TNT were at different nanoscale zero-valent iron initial concentrations. When nanoscale zerovalent iron was added at $1 \mathrm{~g} / \mathrm{L}, 2 \mathrm{~g} / \mathrm{L}, 3 \mathrm{~g} / \mathrm{L}$ and $4 \mathrm{~g} / \mathrm{L}$ respectively, the observed first rate constant of TNT is at $0.012 \mathrm{~h}^{-1}, 0.023 \mathrm{~h}^{-1}, 0.035 \mathrm{~h}^{-1}$ and $0.045 \mathrm{~h}^{-1}$, respectively, where it can be concluded that the first-order kinetics constants increased with increasing of nanoscale zero-valent iron concentration. This phenomenon can be explained by the increased surface area, adsorption and reaction sites on nanoscale zero-valent iron particles, where the TNT reduction was thus accelerated when the concentration was increased. When the data were plotted as the observed rate constant (kobs) against the initial concentration of nanoscale zero-valent iron $\left(\mathrm{C}_{\mathrm{Fe}}\right)$, a strong linear regression equation can be obtained as shown in Fig. 7 and the correlation coefficient $\left(R^{2}\right)$ of this line is $>0.99$, which indicates the observed rate constant $(k \mathrm{obs})$ is proportional to the concentration of nanoscale zero-valent iron and kobs can be improved by increasing the concentration of nano- $\mathrm{Fe} 0$ powder. It is in accordance with the results observed by other workers $^{(32,33)}$, where conventional zero iron powder was applied to reduce chlorinated ethylene and chlorinated acetylene. 


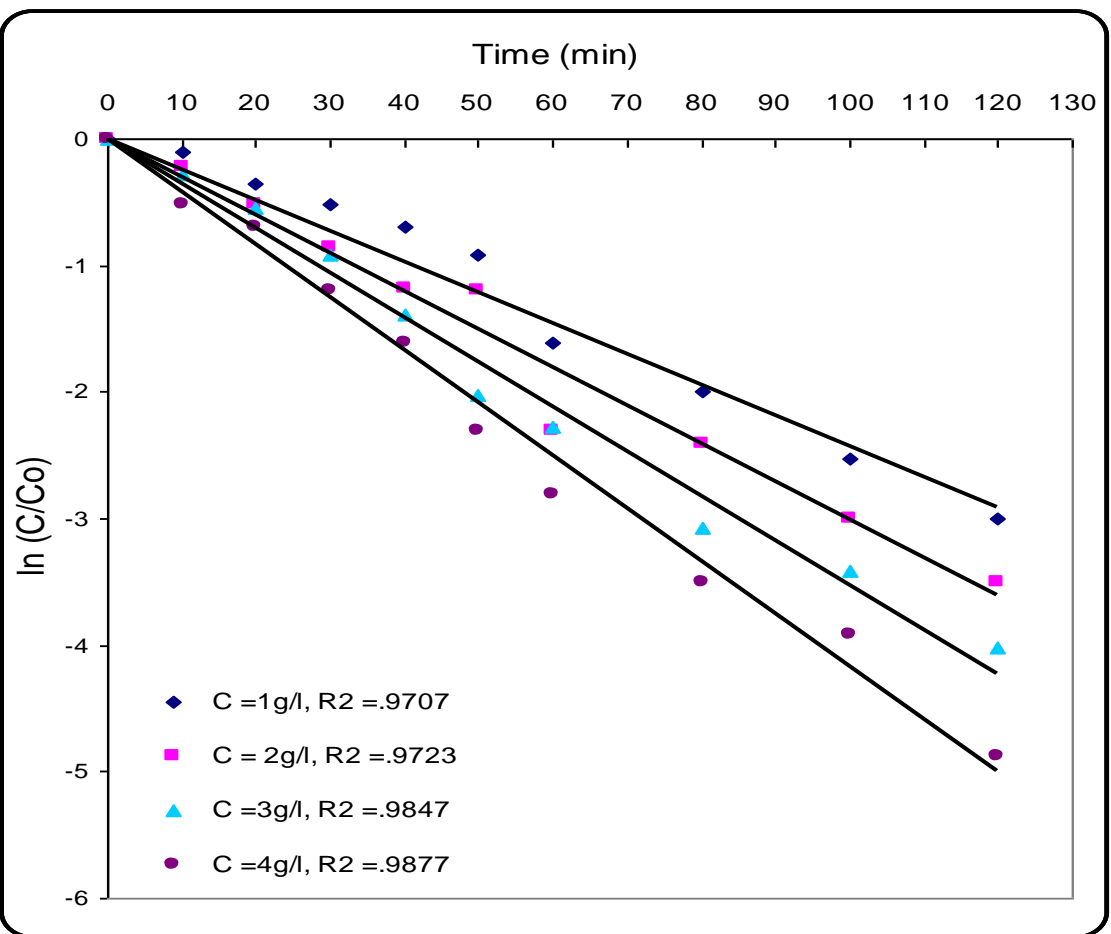

Fig. 6. Effects of concentration of nanoscale zero-valent iron of mixed solution on the rate of TNT reduction time.

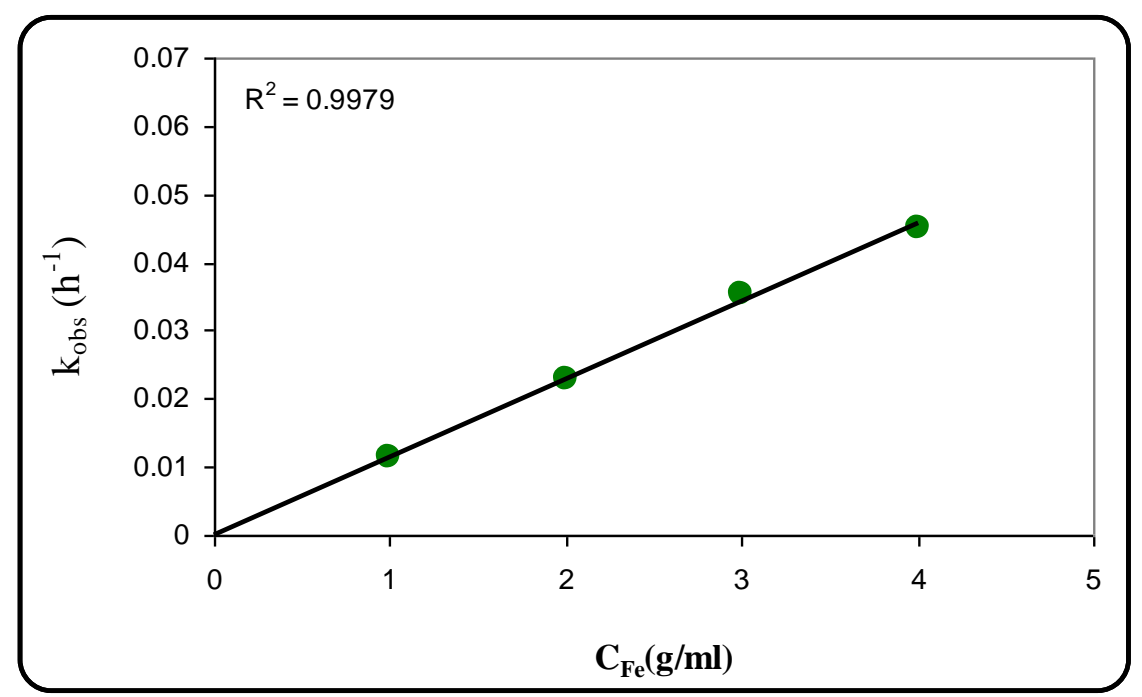

Fig. 7. Relationship of observed rate constant and concentration of nano-iron. 
Effects of $p H$ value on reaction rate of TNT reduced by $n Z V I$

Batch experiments of $100 \mathrm{mg} / \mathrm{l}$ TNT reduced using $3 \mathrm{~g} / \mathrm{L}$ nanoscale zerovalent iron were undertaken in different $\mathrm{pH}$ values at 4.7, 7.4 and 9.7, respectively. Other factors such as rotary rate and the temperature were set at the same as above.

As shown in Fig. 8 the rate of reduction of TNT on nanoscale zero-valent iron was very fast, and the residual concentration of TNT in solution decreased sharply in the first hour. Figure 8 shows the aqueous concentrations of TNT during reductive transformation by nanoscale zero-valent iron in solutions with different $\mathrm{pH}$. At $\mathrm{pH} 4.7$, TNT was rapidly removed from solution; $98.9 \%$ of the initial TNT disappeared after $1 \mathrm{hr}$. Transformation of TNT at $\mathrm{pH} 7.4$ and $\mathrm{pH} 9.7$ was substantially slower. At pH 7.4 complete removal of TNT was observed within $120 \mathrm{~min}$, whereas $27 \%$ of TNT still remained in solution after $120 \mathrm{~min}$ at $\mathrm{pH}$ 9.7. These results indicate that solution $\mathrm{pH}$ has a strong effect on the reduction kinetics of TNT. Accelerated iron corrosion under acidic conditions may be responsible for the enhanced reduction. Therefore, optimum initial $\mathrm{pH}$ values of nanoscale zero-valent iron solution were chosen to be 4.7.

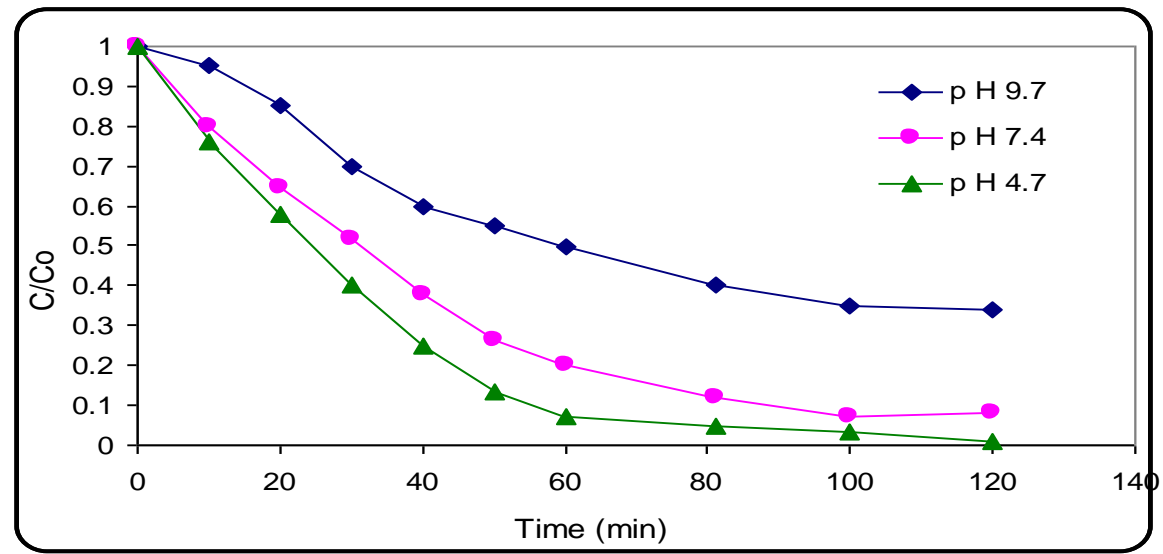

Fig. 8. TNT degradation by nanoscale zero-valent iron with different $\mathrm{pH}$.

Figure 9 shows the relationship between correlation coefficients and rate constants at different $\mathrm{pH}$ values. It can be concluded that the correlation coefficient of each regression line is larger than 0.95, which indicates that the reduction of TNT on nanoscale zero-valent iron also follows the first kinetics model when the $\mathrm{pH}$ value of mixed solutions was changed ${ }^{(13-18)}$. In addition, the reduction rate increased when the $\mathrm{pH}$ was decreased. This is due to hydrogen ions which may react with nanoscale zero-valent iron and consequently will accelerate the reduction rate of $\mathrm{TNT}^{(34,35)}$. Thus, acidic solution may help to accelerate the reaction of TNT reduction on nanoscale zero-valent iron. 


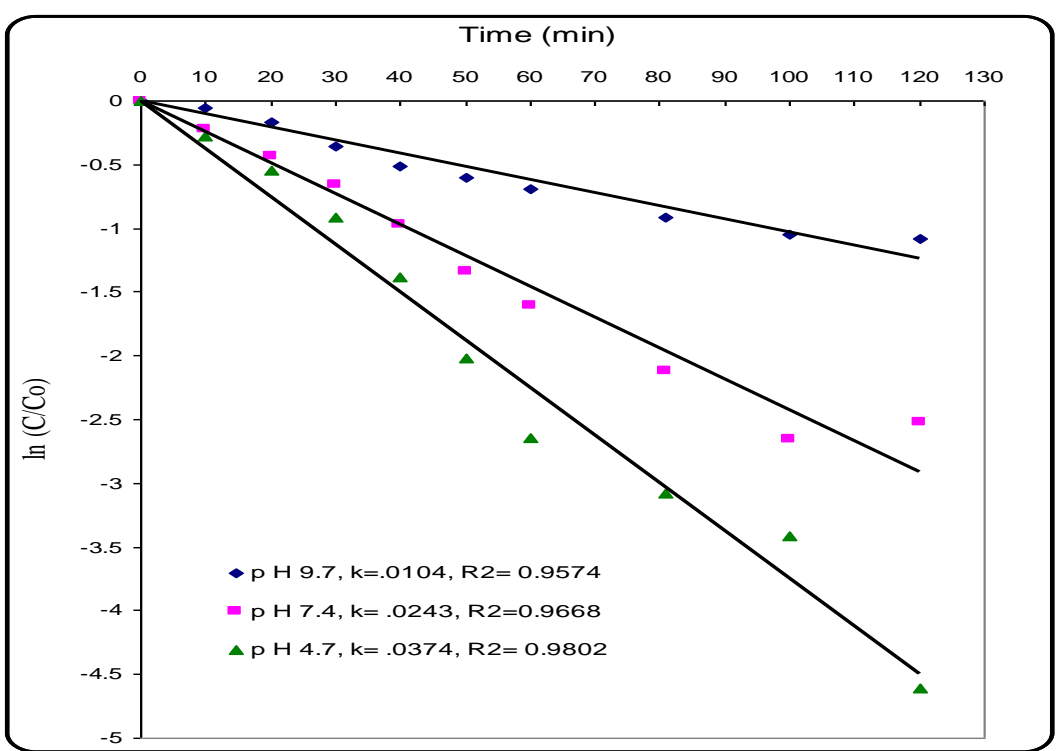

Fig. 9. Effects of pH of nanoscale zero-valent iron of mixed solution on the rate of TNT reduction time.

\section{Comparison of TNT reduction using nanoscale zero-valent iron and conventional} iron

The following batch experiments were undertaken on the same condition as described above to investigate the effects of time on reaction rate of TNT reduction on nanoscale zero-valent iron and conventional iron powder. From comparison of TNT reduction using nanoscale zero-valent iron and conventional iron some conclusions can be drawn: firstly, reduction ratio of TNT using nanoscale zero-valent iron is eleven - fold more than that using conventional iron powder after $2 \mathrm{hr}$ reaction (Fig. 10), and secondly the observed rate constant is 4times larger than that on conventional iron powder (Fig. 11).

In summary, as nanoscale zero-valent iron has high specific surface area and strong adsorption capacity, TNT molecules are absorbed on the surface of nanoscale zero-valent iron in aqueous system, and then adsorbed TNT accepts electrons donated from nanoscale zero-valent iron powder corrosion, and hence the possible reduction pathway may be described as ${ }^{(20)}$ : firstly the TNT molecule accepts six electrons and then one of nitro groups would be reduced to an amino group, where 2-A-4, 6-DNT and 4-A-2, 6-DNT could be produced; secondly these two amino DNT compounds continue to accept six electrons and transform to 2,4DA-6-NT and 2,6-DA-4-NT; finally, these intermediate products (2-A-4,6-DNT; 4A-2,6-DNT; 2,4-DA-6-NT; 2,6-DA-4-NT) accept electrons and all are reduced to $\mathrm{TAT}^{(21)}$. Further work for the confirmation of the reaction mechanism is ongoing.

Egypt. J. Chem. 55, No. 4 (2012) 


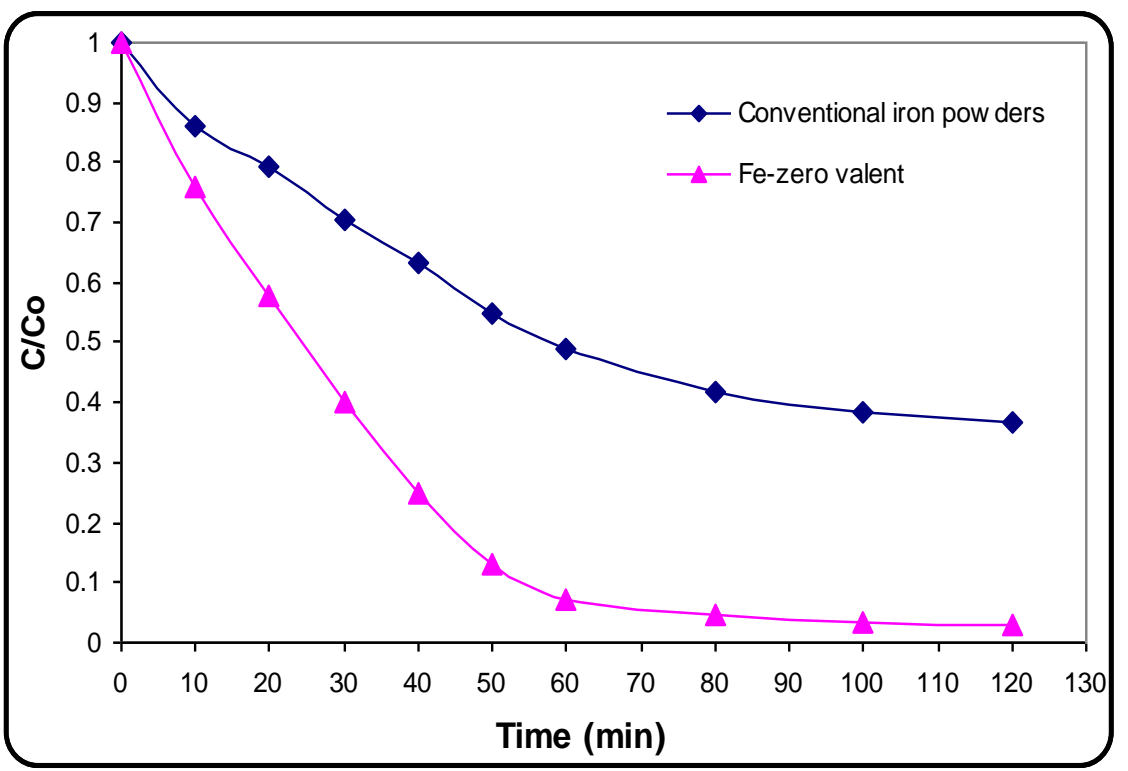

Fig. 10. Comparison of TNT reduction using nanoscale zero-valent iron and conventional iron.

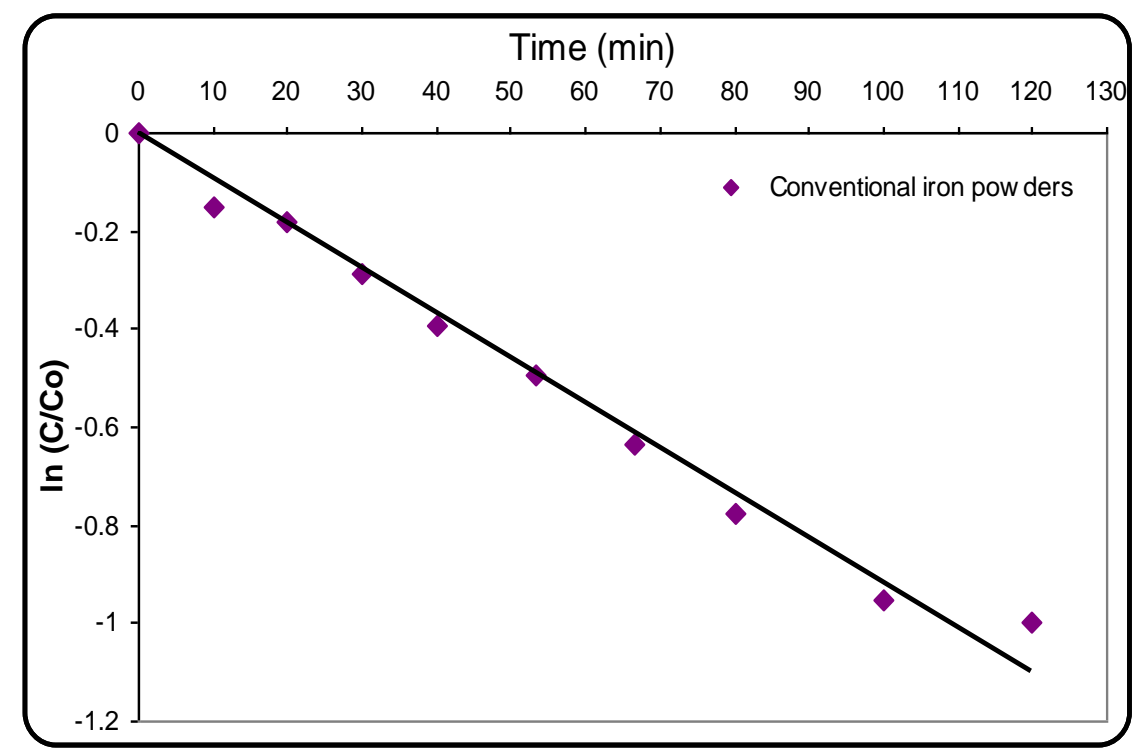

Fig . 11. Relationship between logarithmic plots of TNT concentration versus time on conventional iron. 


\section{Conclusions}

The study shows that TNT in solution can be reduced by nanoscale zerovalent iron and the TNT reduction can be influenced by a number of factors, including the initial concentration of TNT, the $\mathrm{pH}$ of mixed solution and the reaction time. In addition, the reaction rate of TNT reduction on nanoscale zerovalent iron is in accordance with the first-order reaction and the observed rate constant (kobs) is proportional to the concentration of nanoscale zero-valent iron added. Compared with conventional iron powder, reaction rate of TNT reduction on nanoscale zero-valent iron is 4- times faster.

\section{References}

1. Peres, C.M. and Agathos, S.N., Biodegradation of nitroaromatic pollutants: from pathways to remediation. Biotechnol. Ann. Rev. 6 , 197-220 (2000).

2. Pennington, J.C. and Brannon, J.M., Environmental fate of explosives. Themichim. Acta , 384, 163-172 (2002).

3. Ro, K.S., Preston, K.T., Seiden, S. and Bergs, M.A., Remediation composting processprinciples: focus on soils contaminated with explosive compounds. Crit. Rev. Environ. Sci. 28 , 253-243 (1998).

4. Saupe, A., Garvens, H.J. and Heinze, L., Alkaline hydrolysis of TNT and TNT in soil followed by thermal treatment of the hydrolysates. Chemosphere, 36, 1725-1744 (1998).

5. Rajagopal, C. and Kapoor, J.C., Development of adsorptive removal process for treatment of explosives contaminatedwastewater using activated carbon. J. Hazard. Mater. 87, 73-98 (2001).

6. Bose, P., Gaze, W.H. and Massox, D.S., Degradation of RDX by various advanced oxidation processes: I. Reaction rates. Water Res. 32 , 997-1004 (1998).

7. Oh, S.Y., Chiu, P.C., Kim, B.J. and Cha, D.K., Enhancing Fenton oxidation of TNT and RDX through pretreatment with zero-valent iron. Water Res. 37, 4275-4283 (2003)

8. Johnson, T.L., Scherer, M.M. and Tratnyek, P.G., Kinetics of halogenated organic compound degradation by iron metal. Environ. Sci. Technol. 30 , 2634-2640 (1996).

9. Antoine, G., Degradation of benomyl, picloram, and dicamba in a conical apparatus by zero-valent iron power. Chemosphere, 43 , 1109-1117 (2001).

10. Gillham, R.W. and Ohannesin, S.F., Enhanced degradation of halogenated aliphatics by zore-valent iron. Environ. Sci. Technol. 32 , 958-967 (1996).

11. Gu, B., Phelps, T.J., Liang, L., Dickey, M.J., Roh, Y., Kinsall, B.L., Palumbo, A.V. and Jacobs, G.K., Biogeochemical dynamics in zero-valent iron columns: Implications for permeable reactive barriers. Environ. Sci. Technol. 33 , 2170-2177 (1999).

Egypt. J. Chem. 55, No. 4 (2012) 
12. Li, X.Q., Elliott, D.W. and Zhang, W.X., Zero-valent iron nanoparticles for abatement of environmental pollutants: materials and engineering aspects. Crit. Rev. Solid State Mater. Sci. 31, 111-122 (2006).

13. Elliott, D.W. and Zhang, W.X., Field assessment of nanoscale biometallic particles for groundwater treatment. Environ. Sci. Technol. 35, 4922-4926 (2001).

14. Cao, H.S. and Zhang, W.X., Stabilization of chromium ore processing residue (COPR) with nanoscale iron particles. J. Hazard. Mater. 132 , 213-219 (2006).

15. Li, X.Q. and Zhang, W.X., Iron nanoparticles: the core-shell structure and unique properties for $\mathrm{Ni}(\mathrm{II})$ sequestration. Langmuir , 22 , 4638-4642 (2006).

16. Lien, H.L. and Zhang, W.X., Nanoscale iron particles for complete reduction of chlorinated ethenes. J. Colloids Surf. 191 , 97-105 (2001).

17. Zhang, W.X., Nanoscale iron particles for environmental remediation: an over view. $J$. Nanopart. Res. 5, 323-332 (2003).

18. Wang, C.B. and Zhang, W.X., Synthesizing nanoscale iron particles for rapid and complete dechlorination of TCE and PCBs. Environ. Sci. Technol. 31, 2154-2156 (1997).

19. Nurmi, J.T., Characterization and properties of metallic iron nanoparticles: spectroscopy, electrochemistry, and kinetics. Environ. Sci. Technol. 39, 1221-1230 (2005).

20. Choe, S.H., Lee, S.H. and Chang, Y.Y., Rapid reductive destruction of hazardous organic compounds by nanoscale Fe0. Chemosphere , 42, 367-372 (2001).

21. Hundal, L.S., Singh, J., Bier, E.L., Shea, P.J., Comfort, S.D. and Powers, W.L., Removal of TNT and RDX from water and soil using iron metal. Environ. Pollut. 97, 55-64 (1997).

22. Zheng, J.L., Li, J.W. and Chao, F.H., Study progress on aniline, nitrobenzene and TNT biodegradation. Microbiologica , 28 , 85-88 (2001).

23. Jiang, G.B., Analysis method on trinitrotoluene in aqueous solution-sodium sulfite. Spectrophotometry (Chinese), (1992).

24. Chena, S.H., Lioua, R.M., Laia, C.L., Hunga, M.Y., Tsaib, M.H. and Huangb, S.L., Embedded nano-iron polysulfone membrane for dehydration of the ethanol/water mixtures by pervaporation. Desalination , 234 , 221-231 (2008).

25. Yu, T., Lin, J., Xu, J., Chen, T. and Lin, S. , Novel polyacrylonitrile nanocomposites containing Namontmorillonite and nano SiO2 particle. Polymer, 46, 5695-5697 (2005).

26. Mahajan, D., Desai, A., Rafailovich, M., Cui, M.H. and Yang, N.L., Synthesis and characterization of nanosized metals embedded in polystyrene matrix. Composites: Part B, 37, 74-80 (2006). 
27. Sing, K.S.W., Everett, D.H., Haul, R.A.W., Moscou, L., Pierotti, R.A., Rouquero, J. and Siemieniewska, T., Pure Appl. Chem. 57, 603 (1985).

28. Thommes, M., Koehn, R. and Froeba, M., J. Phys. Chem. B, 9104 , 7932 (2000).

29. Cheng, R., Wang, J.L. and Zhang, W.X., Comparison of reductive dechlorination of p-chlorophenol using Fe-0 and nanosized Fe. J. Hazard. Mater. 144, 334-339 (2007).

30. Kanel, S.R., Greneche, J.M. and Choi, H., Arsenic(V) removal kom groundwater using nano scale zero-valent iron as a colloidal reactive barrier material. Environ. Sci. Technol. 40, 2045-2050 (2006).

31. Bandstra, J.Z., Miehr, R., Johnson, R.L. and Tranyek, P.G., Reduction of 2,4,6trinitrotoluene by iron metal: kinetic controls on product distributions in batch experiments. Environ. Sci. Technol. 39, 230-238 (2005).

32. Gllham, R.W. and O'Hannesin, S.F., Enhanced degradation of halogenated aliphatics by zero-valent iron. Groundwater, 32, 958-967 (1994).

33. Arnokl, W.A. and Roberts, A.L., Pathways and kinetics chlorinated ethylene and chlorinated acetylene reaction with Fe0 particles. Environ. Sci. Technol. 34, 17941805 (2000).

34. Oh, S.Y., Chiu, P.C., Kim, B.J. and Chiu, D.K., Zero-valent iron pretreatment for enhancing the biodegradability of RDX. Water Res. 39, 5027-5032 (2005).

35. Liu, Y.Q. and Lowry, G.V., Effect of particle age (Fe-0 content) and solution pH on NZVI reactivity: H-2 evolution and TCE dechlorination. Environ. Sci. Technol. 40, 6085-6090 (2006). 


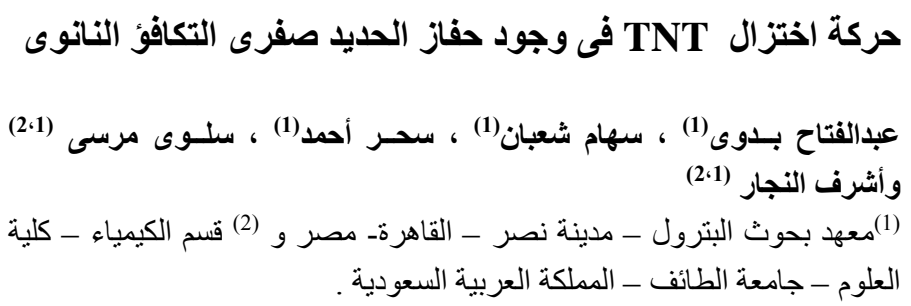

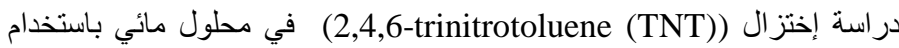

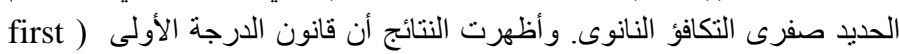

(order reaction law

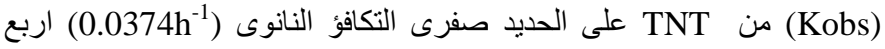

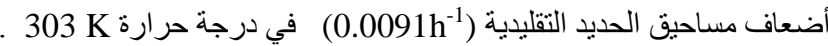

معدل الثابت لأختزال TNT على الحديد صفرى التكافؤ النانوى يمكن أيضا

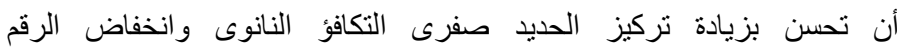

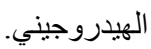

